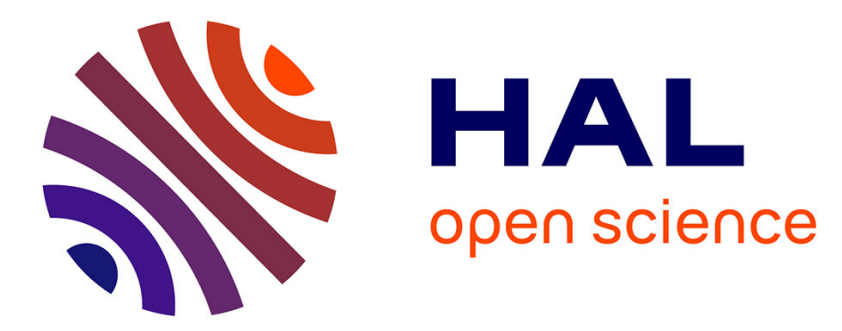

\title{
The influence of iodide on glass transition temperature of high-pressure nuclear waste glasses
}

\author{
Valentin Jolivet, Yann Morizet, Jonathan Hamon, Michael Paris, Tomo
}

Suzuki-Muresan

\section{- To cite this version:}

Valentin Jolivet, Yann Morizet, Jonathan Hamon, Michael Paris, Tomo Suzuki-Muresan. The influence of iodide on glass transition temperature of high-pressure nuclear waste glasses. Journal of the American Ceramic Society, 2021, 104 (3), pp.1360-1369. 10.1111/jace.17571 . hal-03052155

\section{HAL Id: hal-03052155 \\ https://hal.science/hal-03052155}

Submitted on 15 Dec 2020

HAL is a multi-disciplinary open access archive for the deposit and dissemination of scientific research documents, whether they are published or not. The documents may come from teaching and research institutions in France or abroad, or from public or private research centers.
L'archive ouverte pluridisciplinaire HAL, est destinée au dépôt et à la diffusion de documents scientifiques de niveau recherche, publiés ou non, émanant des établissements d'enseignement et de recherche français ou étrangers, des laboratoires publics ou privés. 


\section{The influence of iodide on glass transition temperature of high-pressure}

\section{nuclear waste glasses}

\section{Valentin JOLIVET ${ }^{1,2,3}$, Yann MORIZET ${ }^{1,2^{*}}$, Jonathan HAMON ${ }^{2}$, Michael PARIS ${ }^{2}$, Tomo SUZUKI-MURESAN ${ }^{3}$}

${ }^{1}$ Laboratoire de Planétologie et Géodynamique de Nantes (LPGN) UMR 6112 CNRS, Université de Nantes, Nantes Atlantique Universités, 2 rue de la Houssinière, 44322 Nantes, France.

${ }^{2}$ Université de Nantes, CNRS, Institut des Matériaux Jean Rouxel, IMN, F-44000 Nantes, France

${ }^{3}$ SUBATECH, Université de Nantes, IMT Atlantique, CNRS/IN2P3, 4 rue Alfred Kastler, B.P. 207222, Nantes, France

*Corresponding author: Yann Morizet

Postal address:

Laboratoire de Planétologie et Géodynamique de Nantes (LPG), UMR-CNRS 6112, Université de Nantes.

2 rue de la Houssinière, 44322 Nantes Cedex (FRANCE)

phone: +33 (0) 251125491

fax: $+33(0) 251125268$

*E-mail: yann.morizet@univ-nantes.fr 


\begin{abstract}
The glass transition temperature $\left(\mathrm{T}_{\mathrm{g}}\right)$ is a key parameter to investigate for application in nuclear waste immobilization in borosilicate glasses. $\mathrm{T}_{\mathrm{g}}$ for several glasses containing iodine (I) has been measured in order to determine the I effect on $\mathrm{T}_{\mathrm{g}}$. Two series of glass composition (ISG and NH) containing up to $2.5 \mathrm{~mol} \%$ I and synthesized under high-pressure $(0.5$ to $1.5 \mathrm{GPa})$ have been investigated using Differential Scanning Calorimetry. The I local environment in glasses has been determined using X-ray Photoelectron Spectroscopy and revealed that I is dissolved under its iodide form $\left(\mathrm{I}^{-}\right)$.

Results show that $\mathrm{T}_{\mathrm{g}}$ is decreased with the I addition in the glass in agreement with previous results. We also observed that this $\mathrm{T}_{\mathrm{g}}$ decrease is a strong function of glass composition. For $\mathrm{NH}$, 2.5 mol.\% I induces a decrease of $24^{\circ} \mathrm{C}$ in $\mathrm{T}_{\mathrm{g}}$ whereas for ISG $1.2 \mathrm{~mol} \%$ decreases the $\mathrm{T}_{\mathrm{g}}$ by $64^{\circ} \mathrm{C}$. We interpret this difference as the result of the I dissolution mechanism and its effect on the polymerization of the boron network. The I dissolution in ISG is accompanied by a depolymerization of the boron network whereas it is the opposite in NH. Although ISG corresponds to a standardized glass, for the particular case of I immobilization it appears less adequate than $\mathrm{NH}$ considering that the decrease in $\mathrm{T}_{\mathrm{g}}$ for $\mathrm{NH}$ is small in comparison to ISG.
\end{abstract}

\title{
1 Introduction
}

There has been a growing interest in the incorporation of Iodine (I) in glasses in the past few years, especially in the field of Earth sciences ${ }^{1,2}$ and in the nuclear waste glasses community. ${ }^{3-8}$ I has an active radioisotope $\left({ }^{129} \mathrm{I}\right)$ that is produced from the nuclear fission of actinides..${ }^{9,10}{ }^{129} \mathrm{I}$ represents a major troublesome element due to its high mobility in the environment, low affinity for claystone and its long half-life (15.7 My). ${ }^{11-13}$ Despite its low activity, ${ }^{129} \mathrm{I}$ is considered to be 
the main dose contributor in geological disposal. ${ }^{10}$ Therefore, many research efforts have focused on searching for a specific matrix capable to accommodate and to immobilize permanently I radioisotope (see Riley et al. ${ }^{5}$ and references therein). From the numerous possible matrices to immobilize ${ }^{129}$ I, borosilicate glasses represent a highly considered solution. However, recent experimental studies ${ }^{4,14,15}$ showed that I is strongly volatile and under ambient pressure conditions (or just above ambient pressure), the I retained in glass does not exceed 0.5 mol.\%. Recently, a protocol using high-pressure synthesis, greatly improved the amount of I dissolved in borosilicate glasses. For instance, Jolivet et al. ${ }^{8}$ produced glasses with composition relevant to nuclear waste immobilization with dissolved I content up to $2.5 \mathrm{~mol} . \%$; therefore representing a potential solution for the permanent immobilization of I radioisotopes.

Understanding the change in nuclear waste glass physical properties (i.e. viscosity and density) is of prime interest for determining the stability and durability through time of the radioactive matrices. $T_{g}$ represents the transformation of a liquid upon cooling into a glass. ${ }^{16}$ This transformation is kinetically activated as crystallization is avoided upon fast cooling. ${ }^{16}$ Dingwell and $\mathrm{Webb}^{17}$ also inferred the fact that $\mathrm{T}_{\mathrm{g}}$ represents a proxy to melt viscosity and corresponds to the temperature at which $\log \eta=12$ Pa.s. Therefore, it has a kinetic and thermodynamic definition and is strongly function of the sample thermal history. ${ }^{16-18}$ At a given cooling rate, $\mathrm{T}_{\mathrm{g}}$ is dependent on the glass composition. For the particular case of borosilicate glasses, there has been extensive work in determining the change in $\mathrm{T}_{\mathrm{g}}$ as a function of several key composition parameters. It has been shown that borosilicate glass $\mathrm{T}_{\mathrm{g}}$ is affected by many compositional parameters such as 1 ) the $\mathrm{R}$ and $\mathrm{K}$ values defined as the ratio $\mathrm{Na} 2 \mathrm{O} / \mathrm{B}_{2} \mathrm{O}_{3}$ and $\mathrm{SiO}_{2} / \mathrm{B}_{2} \mathrm{O}_{3}$, respectively; ${ }^{19,20}$ 2) the presence of $\mathrm{Al}_{2} \mathrm{O}_{3},{ }^{21,22}$ and 3) the nature of the network-modifying cation. $^{23-25}$ 
Regardless of the major element chemical composition (i.e. silicate or borosilicate glasses), it has been demonstrated that the presence of volatile species influences $\mathrm{T}_{\mathrm{g}}$. For instance, $\mathrm{H}_{2} \mathrm{O}$ provokes a dramatic decrease in $\mathrm{T}_{\mathrm{g}}{ }^{26-29}$ whereas $\mathrm{CO}_{2}$ only weakly decreases $\mathrm{T}_{\mathrm{g}}{ }^{30,31}$ Currently, the effect of halogens on borosilicate glasses $T_{g}$ is poorly understood. For a wide range of glass compositions, it has been shown that chlorine decreases $T_{\mathrm{g}}{ }^{32-35}$ The effect of iodine on $\mathrm{T}_{\mathrm{g}}$ is less constrained. Recent work on B-rich glasses showed that I decreases $\mathrm{T}_{\mathrm{g}}{ }^{7}$ It appears consistent with the fact that I is considered as a melting accelerator and fining agent. ${ }^{3,36}$ However, up to now, investigation of the I effect on $\mathrm{T}_{\mathrm{g}}$ for borosilicate glass composition relevant to nuclear waste immobilization is not available.

The change in $\mathrm{T}_{\mathrm{g}}$ finds its origin in structural changes at microscopic scale. For silicate glasses, it has been demonstrated that increasing the degree of polymerization of the structure induces an increase in $\mathrm{T}_{\mathrm{g}} .{ }^{28,37} \mathrm{Often}$ expressed as the $\mathrm{NBO} / \mathrm{T}$ corresponding to the ratio between the Non-Bridging Oxygen and Tetrahedron concentrations, ${ }^{38}$ the degree of polymerization represents a major control on many physical properties such as viscosity, density, diffusion, or electrical conductivity. ${ }^{38,39-41}$ For borosilicate glasses, the relationship between macroscopic physical properties and microscopic structural changes is a little more complex considering that there are the coexistence and interplay between two forming networks: silicate and borate networks. ${ }^{42-48}$

Specifically, two coexisting structural units form the borate network: trigonal $\mathrm{BO}_{3}$ and tetragonal $\mathrm{BO}_{4}{ }^{49}$ The $\mathrm{N}_{4}$ parameter is defined as $\left[\mathrm{BO}_{4}\right] /\left[\mathrm{BO}_{4}+\mathrm{BO}_{3}\right]$ and represents the distribution of boron structural units. Early models used the $\mathrm{N}_{4}$ for describing the structure of borosilicate glasses ${ }^{42}$ and evolution of the $\mathrm{N}_{4}$ correlates to the stoichiometry of the glass composition (i.e. $\mathrm{R}$ and $\mathrm{K}$ value). The $\mathrm{BO}_{4}$ units being more polymerized than $\mathrm{BO}_{3}$ units, ${ }^{50}$ the $\mathrm{N}_{4}$ 
value represents a key parameter for the definition of a nuclear waste glass composition (i.e. a high $\mathrm{N}_{4}$ value is sought for better glass stability). Previous investigation showed that $\mathrm{T}_{\mathrm{g}}$ is a complex function of the $\mathrm{N}_{4}{ }^{51}$ Considering that Jolivet et al.${ }^{8}$ demonstrated that $\mathrm{I}$ is influencing the structure of the borosilicate glasses (i.e. $\mathrm{N}_{4}$ ), therefore we expect I to influence the $\mathrm{T}_{\mathrm{g}}$ value.

In the present work, we investigated several I-bearing glasses of different compositions reported in Jolivet et al. ${ }^{8}$ for determining $\mathrm{T}_{\mathrm{g}}$. The relationship between $\mathrm{I}$ content and $\mathrm{T}_{\mathrm{g}}$ is established. We discussed the change in $\mathrm{T}_{\mathrm{g}}$ from the structural viewpoint and the change in $\mathrm{N}_{4}$ value associated with the I dissolution. An outlook is also proposed for defining a glass matrix specific for the I accommodation based on the change in $\mathrm{T}_{\mathrm{g}}$.

\section{Experimental methods}

\subsection{Samples}

We investigated I-bearing glass samples reported in Jolivet et al. ${ }^{8}$. The samples were synthesized under high-pressure conditions in piston cylinder apparatus in equilibrium with $\mathrm{I}_{2}$ as a fluid phase. Several experimental charges were also prepared without $\mathrm{I}_{2}$ in order to constrain the possible effect of pressure on $\mathrm{T}_{\mathrm{g}}$. Synthesis procedure and intensive conditions are fully described in Jolivet et al. ${ }^{8}$. Experimental pressure ranges from 0.5 to $1.5 \mathrm{GPa}$ and temperature from 1300 to $1400^{\circ} \mathrm{C}$. The samples were quenched from high temperature run condition at a rate of $\sim 100^{\circ} \mathrm{C} / \mathrm{s}$. in the first five hundred degrees. The quench rate is considered to be the same for all samples.

In the present work, we studied two glass compositions with the following nomenclature: ISG and NH. The ISG (International Simple Glass) is a standard simulant for nuclear waste glass

studies. ${ }^{52-56}$ Its composition is similar to strongly polymerized High-Level Waste glasses. ${ }^{57} 60.2$ mol.\% $\mathrm{SiO}_{2}, 3.8 \mathrm{Al}_{2} \mathrm{O}_{3}, 16.0 \mathrm{~B}_{2} \mathrm{O}_{3}, 5.7 \mathrm{CaO}, 12.6 \mathrm{Na}_{2} \mathrm{O}, 1.7 \mathrm{ZrO}_{2}$. The $\mathrm{NH}$ glass is similar to 
depolymerized Low-Activity Waste glasses (LAW). ${ }^{4,5}$ Its composition is presented in Jolivet et al. ${ }^{48}$, and I-doped high-pressure samples are described in Jolivet et al. ${ }^{8}: 43.1$ mol.\% $\mathrm{SiO}_{2}, 9.5$ $\mathrm{Al}_{2} \mathrm{O}_{3}, 15.1 \mathrm{~B}_{2} \mathrm{O}_{3}, 8.0 \mathrm{CaO}, 24.2 \mathrm{Na}_{2} \mathrm{O}$. In the present work, we used the same sample nomenclature as in Jolivet et al. ${ }^{8}$

The chemical composition of the I-bearing samples was determined with a JEOL JSM 5800LV Scanning Electron Microscope, equipped with a SDD SAMx Energy Dispersive Spectrometer (SEM EDS). The ISG composition served as a reference for chemical analyses to correct instrumental drift. The NH initial composition has also been characterized using Inductively Coupled Plasma Optical Emission Spectroscopy (ICP OES). The measured I content is up to 1.2 and $2.5 \mathrm{~mol} \%$ for ISG and $\mathrm{NH}$ glasses, respectively.

\subsection{Differential Scanning Calorimetry (DSC)}

Differential Scanning Calorimetry (DSC) analyses were performed using a SETARAM Setsys Evolution 16/18 TGA-DSC (DSC Thermo-Gravimetric Analysis) at the Institut Mines Telecom Atlantique (IMT Atlantique). The DSC was calibrated against the melting enthalpy of lead. We used an empty crucible in every run, blank or experiment as a reference. We performed a blank run for two sample runs, with the sample crucible filled with $\sim 3 \mathrm{mg}$ of alumina powder to determine the baseline of the DSC device. All samples were gently crushed and $\sim 16-17 \mathrm{mg}$ of glass sample was analyzed each time. We used the same Pt crucible for all experiments, and poured with alumina powder prior to glass powder. The heating profile was a heating ramp from ambient temperature to $300^{\circ} \mathrm{C}$ at $20^{\circ} \mathrm{C} / \mathrm{min}$, then the heating rate was lowered at $10^{\circ} \mathrm{C} / \mathrm{min}$, from 300 to $640^{\circ} \mathrm{C}$. The furnace was purged with inert gas $\left(\mathrm{N}_{2}\right)$ with a flow of $20 \mathrm{~mL} / \mathrm{min}$ during the heating cycle. Due to the presence of volatiles in these glasses, we did not repeat each sample profile, as iodine might escape during the repeated experiments. 
The $T_{\mathrm{g}}$ was determined using the variation of the measured heat flow $(\mathrm{mW})$ and the two tangents method using the Calisto@ software implemented procedure. ${ }^{31}$ The method for determining $T_{g}$ is shown in Figure 1. A blank spectrum is subtracted from the sample spectrum (Figure 1A) prior to determine the value of $\mathrm{T}_{\mathrm{g}}$ (Figure 1B). The corrected DSC curves were treated mathematically with a smoothing function.
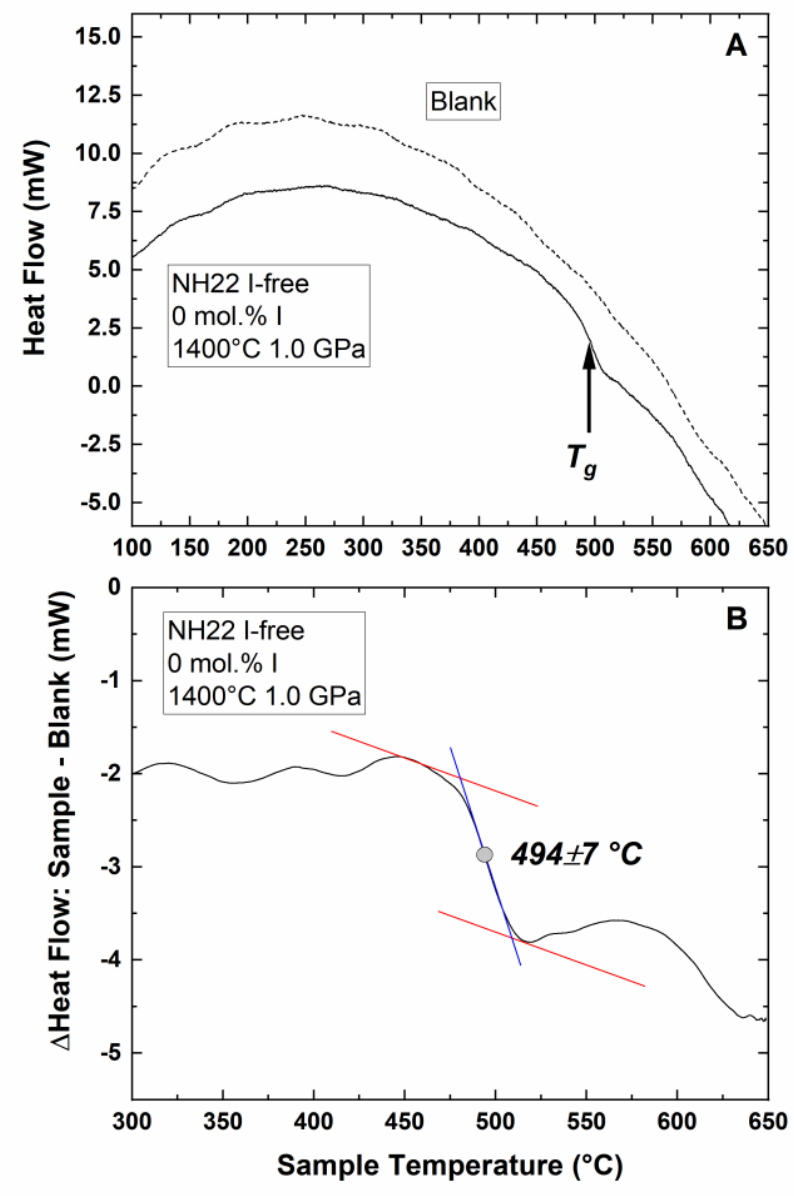

Figure 1: A) Heat flow curve obtained on NH22 I-free and corresponding blank curve at 10K/min as heating rate. The location of $T_{g}$ is indicated and shown by the heat flow curve inflexion. B) $T_{g}$ determination on the heat flow curve after blank subtraction. The double tangent method has been used; the error on the determination of $\mathrm{T}_{\mathrm{g}}$ is $\pm 7^{\circ} \mathrm{C}$ as given by the software. 


\subsection{X-ray Photoelectron Spectroscopy (XPS)}

X-Ray Photoelectron Spectroscopy (XPS) was conducted on several glass samples at the Institut des Matériaux Jean Rouxel (IMN Jean Rouxel). We carried out the XPS measurements for obtaining the I speciation in the investigated glasses. Several crystalline compounds (NaI, $\mathrm{NaIO}_{3}$ and $\mathrm{CaI}_{2} \mathrm{O}_{6}$ ) were also analyzed, serving as a standard for I speciation in I-bearing borosilicate glasses. We could not acquire solid crystalline $\mathrm{I}_{2}$ XPS spectrum due to the strong sublimation of $I_{2}$ under high vacuum conditions.

The XPS analyses were carried out on a Kratos Nova spectrometer and a Kratos Axis Ultra spectrometer using a monochromatic $\mathrm{Al} \mathrm{K} \alpha$ radiation operating at $1486.6 \mathrm{eV}(15 \mathrm{kV}, 20 \mathrm{~mA})$. Due to the low electrical conductivity of our samples, we employed a charge neutralizer for each analysis. The glass chips $\left(\sim 3 \times 3 \mathrm{~mm}^{2}\right)$ showing an unprepared surface from the bulk of the experimental charge were loaded into the sample chamber and at high vacuum $\left(<10^{-6} \mathrm{~Pa}\right)$. The spot size on the sample is $300 \times 700 \mu \mathrm{m}$ area of analyses. Survey spectra were recorded at a pass energy of $160 \mathrm{eV}$ corresponding to an overall instrument resolution measured on silver Fermi edge of $1.95 \mathrm{eV}$ and a step of $0.5 \mathrm{eV}$ from -5 to $1200 \mathrm{eV}$. High-resolution spectra of the I $3 \mathrm{~d}$ core levels were recorded with an instrument resolution measured on silver Fermi of $0.49 \mathrm{eV}$ and a step of $0.1 \mathrm{eV}$ at a pass energy of $20 \mathrm{eV}$. Several I 3d acquisitions were performed and the spectra were averaged. We did not find any modification of each individual acquisition suggesting that the glass was stable under the X-ray beam. The energy shift calibration was performed on the adventitious $\mathrm{C} 1 \mathrm{~s}$ in the binding energy at $284.8 \mathrm{eV}$. All spectra were treated with CasaXPSC software. All spectra were fitted with a U2 Tougaard function ${ }^{58}$ for the background and with a pseudo-Voigt function for the various peaks. Only the I $3 \mathrm{~d}_{5 / 2}$ peak on the I $3 \mathrm{~d}$ region was fitted, owing to its higher intensity as compared to the one for the $\mathrm{I} 3 \mathrm{~d}_{3 / 2} .{ }^{5,60}$ 


\section{Results}

\subsection{Iodine speciation in glasses from XPS}

Figure 2 shows typical I $3 \mathrm{~d}_{5 / 2}$ XPS spectra obtained on several glasses (ISG and NH) and several crystalline compounds (iodide and iodate). Investigated iodates $\left(\mathrm{NaIO}_{3}\right.$ and $\left.\mathrm{CaI}_{2} \mathrm{O}_{6}\right)$ in which I is present under its cationic form $\mathrm{I}^{5+}$, exhibit a single highly symmetric peak located at $\sim 624 \mathrm{eV}$, whereas iodide (NaI) in which I is present under its anionic form $\mathrm{I}^{-}$has a highly symmetric peak at $\sim 619 \mathrm{eV}$. This observation is consistent with previous investigations on similar compounds. ${ }^{61}$ According to the Handbook of XPS, ${ }^{61}$ crystalline $\mathrm{I}_{2}$ (I under $\mathrm{I}^{0}$ form) exhibits a peak located at $\sim 620 \mathrm{eV}$, hence slightly overlapping with $\mathrm{I}^{-}$peak.

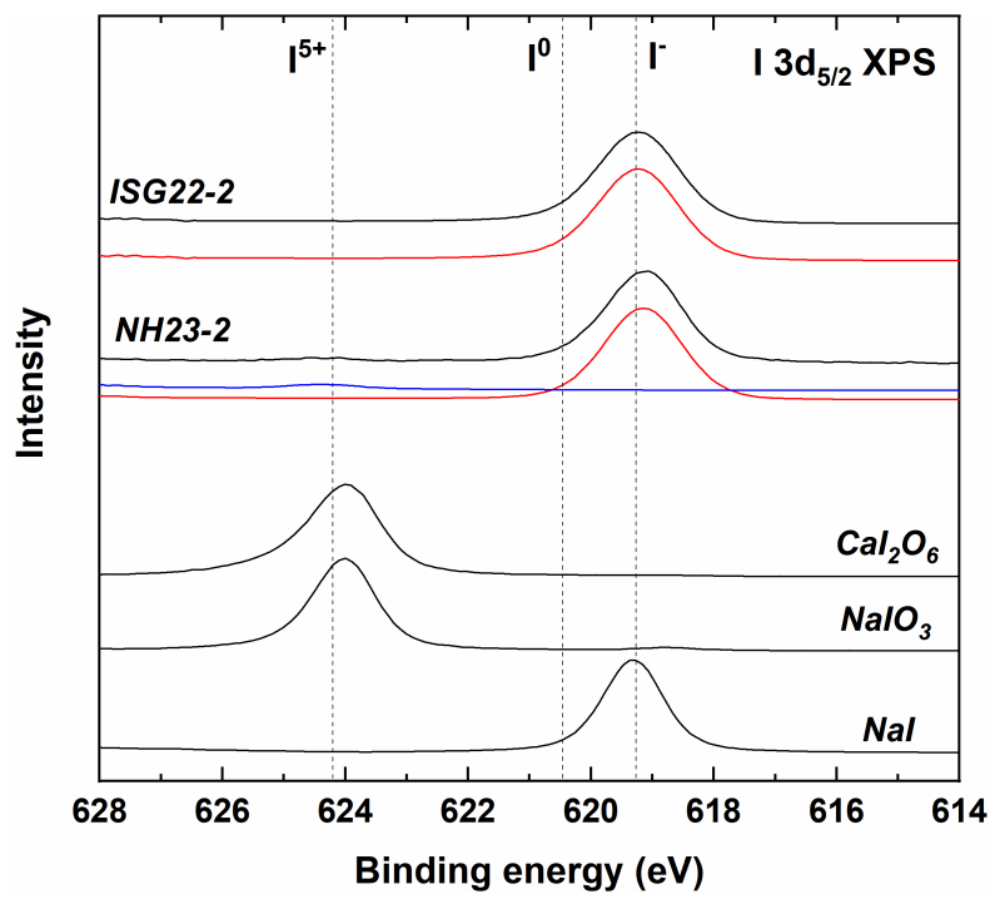

Figure 2: I 3d5/2 XPS spectra collected on several I-bearing glasses (ISG22-2 and NH23-2) and crystalline compounds $\left(\mathrm{NaI}, \mathrm{NaIO}_{3}, \mathrm{CaI}_{2} \mathrm{O}_{6}\right)$ serving as fingerprint for determining the I local environment: $\mathrm{I}^{-}$at $\sim 619 \mathrm{eV}^{\text {or I }} \mathrm{I}^{5+}$ at $\sim 624 \mathrm{eV}$. The subsequent simulation of the glass XPS spectra is also shown. 
For glasses, regardless of the glass composition, I is dissolved mostly as I־ species. We observed a slight asymmetry on the glass XPS spectra suggesting that there is a small amount of I dissolved as $I^{0}$. From subsequent simulation of the XPS spectra (Figure 2), we determined that $\mathrm{I}^{-}$ is present at a proportion $>90 \%$. The $\mathrm{NH} 23-2$ spectrum shows a very weak peak at $\sim 624 \mathrm{eV}$ (see Figure 2) indicating the presence of $\mathrm{I}^{5+}$ under low concentration (3.5\%). Speciation results are provided in Table 1. Overall, I is dissolved as iodide in the investigated glasses. We conducted the high-pressure syntheses without controlling the oxygen fugacity $\left(f \mathrm{O}_{2}\right)$ conditions and the $f \mathrm{O}_{2}$ has been estimated around $1 \log$ unit above the Quartz-Fayalite-Magnetite solid buffer. ${ }^{62}$ Previous studies ${ }^{4,15}$ showed that $\mathrm{I}^{-}$is also the main dissolved I species in glasses synthesized under atmospheric conditions (more severe oxidizing conditions). Therefore, our results are consistent and the observed change in $\mathrm{T}_{\mathrm{g}}$ as a function of $\mathrm{I}$ content is caused by the presence of $\mathrm{I}^{-}$ or the structural associated changes. 
Table 1: Experimental conditions, iodine content, boron speciation and glass transition temperature results.

\begin{tabular}{|c|c|c|c|c|c|c|}
\hline Sample & Temperature $\left({ }^{\circ} \mathrm{C}\right)$ & Pressure (GPa) & I content (mol.\%) & I speciation & $\mathrm{N}_{4}^{*}$ & $\mathrm{~T}_{\mathrm{g}}\left({ }^{\circ} \mathrm{C}\right)$ \\
\hline & & & & & & $577 \pm 7$ \\
\hline \multirow[t]{2}{*}{ ISG } & 1400 & 0.0001 & 0 & & 0.5 & \\
\hline & & & & & & 587 \\
\hline ISG 21-1 & 1400 & 0.5 & $0.9(0.1)$ & n.d. & 0.47 & 540 \\
\hline ISG 21-2 & 1400 & 0.5 & $0.7(0.2)$ & n.d. & 0.48 & 550 \\
\hline ISG 22 I-free & 1400 & 1 & 0 & & 0.51 & 578 \\
\hline ISG 12 & 1300 & 1 & $1.0(0.3)$ & n.d. & 0.48 & 548 \\
\hline ISG 22-1 & 1400 & 1 & $1.0(0.2)$ & n.d. & 0.47 & 557 \\
\hline ISG 22-2 & 1400 & 1 & $1.2(0.2)$ & 1.00 & 0.46 & 518 \\
\hline ISG 13 & 1300 & 1.5 & $0.9(0.2)$ & n.d. & 0.47 & 558 \\
\hline $\mathrm{NH}$ & 1400 & 0.0001 & 0 & & 0.37 & 504 \\
\hline NH 22 I-free & 1400 & 1 & 0 & & 0.41 & 494 \\
\hline NH 22-1 & 1400 & 1 & $1.0(0.1)$ & 0.91 & 0.42 & 493 \\
\hline NH 22-2 & 1400 & 1 & $2.0(0.3)$ & n.d. & 0.44 & 471 \\
\hline NH 23 I-free & 1400 & 1.5 & 0 & & 0.41 & 491 \\
\hline NH 21-2 & 1400 & 0.5 & $1.7(0.1)$ & n.d. & 0.44 & 470 \\
\hline NH 23-1 & 1400 & 1.5 & $1.9(0.3)$ & 0.96 & 0.45 & 493 \\
\hline NH 23-2 & 1400 & 1.5 & $2.5(0.2)$ & 0.97 & 0.45 & 480 \\
\hline
\end{tabular}

${ }^{*}$ The $\mathrm{N}_{4}$ values have been taken from Jolivet et al. ${ }^{8}$. The italic values are estimated $\mathrm{N}_{4}$ values from linear regression. 


\subsection{DSC curves as a function of iodine content and glass composition}

Figure 3 shows several DSC curves obtained on the investigated glasses. The $\mathrm{T}_{\mathrm{g}}$ is represented on each curve and I content is also given. The obtained $\mathrm{T}_{\mathrm{g}}$ values are reported in Table 1. The error associated with the $\mathrm{T}_{\mathrm{g}}$ determination after smoothing of the DSC curve and given by the software is $\pm 7^{\circ} \mathrm{C}$.

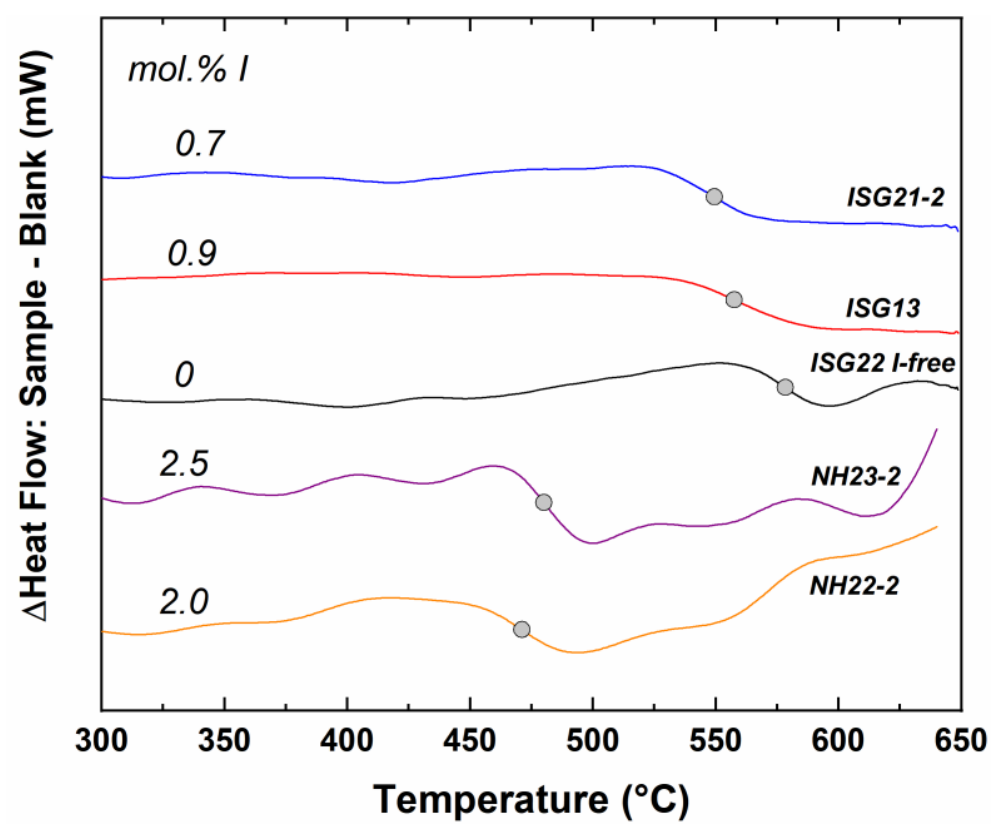

Figure 3: Heat flow DSC curves acquired on I-bearing glasses after blank subtraction. We applied a slight smoothing function to the obtained curve. Curves for ISG are shown at the top and NH at the bottom. The I content is also indicated. The determined $T_{g}$ is shown on each curve and shows that $\mathrm{T}_{\mathrm{g}}$ is a function of both glass composition and I content.

The first striking observation is that there is a clear difference in $T_{g}$ values in between the compositions. The ISG glasses with and without I have a higher $\mathrm{T}_{\mathrm{g}}$ values $\left(>550^{\circ} \mathrm{C}\right)$ than the equivalent $\mathrm{NH}\left(<500^{\circ} \mathrm{C}\right)$. As a standardized glass composition, ISG has been widely studied. 
Previous works determined $\mathrm{T}_{\mathrm{g}}$ value for ISG in the range $570-577^{\circ} \mathrm{C} .{ }^{63-65}$ In the present work, we have determined two $\mathrm{T}_{\mathrm{g}}$ values for ISG from replicate measurements at 577 and $587^{\circ} \mathrm{C}$ that are in very good agreement with previously reported values, therefore suggesting that our approach is adequate for determining $\mathrm{T}_{\mathrm{g}}$.

In Figure 3, it appears that adding I to the ISG glasses induces a decrease in the $\mathrm{T}_{\mathrm{g}}$. For instance, ISG22 $\mathrm{I}$-free has a $\mathrm{T}_{\mathrm{g}}=578^{\circ} \mathrm{C}$ and $\mathrm{ISG} 22-2$ with $1.2 \mathrm{~mol} \% \mathrm{I}$ has a $\mathrm{T}_{\mathrm{g}}=518^{\circ} \mathrm{C}(\mathrm{see}$ Table 1). Considering that both glasses were synthesized at $1.0 \mathrm{GPa}$, the change of $60^{\circ} \mathrm{C}$ in $\mathrm{T}_{\mathrm{g}}$ is ascribed to the presence of $\mathrm{I}^{-}$in the glass structure and its effect on the ISG glass structure. For $\mathrm{NH}$ glasses, the same behavior is observed with a decrease in $\mathrm{T}_{\mathrm{g}}$ with increasing I content. However, the $\mathrm{T}_{\mathrm{g}}$ decrease for $\mathrm{NH}$ appears less important than for ISG composition. For instance, for $1.0 \mathrm{GPa}$ pressure, $\mathrm{NH} 22 \mathrm{I}$-free has a $\mathrm{T}_{\mathrm{g}}=494^{\circ} \mathrm{C}$ and $\mathrm{NH} 22-2$ with $2.0 \mathrm{~mol} . \% \mathrm{I}_{\text {has }}$ a $\mathrm{T}_{\mathrm{g}}=$ $471^{\circ} \mathrm{C}$. For almost twice the I amount, $\mathrm{T}_{\mathrm{g}}$ decreases by a third in $\mathrm{NH}$ as compared to ISG glass. The change in $\mathrm{T}_{\mathrm{g}}$ values as a function of I content is shown in Figure 4. There is a clear decrease in $\mathrm{T}_{\mathrm{g}}$ value as a function of I content for both compositions. As mentioned, the slope in the $\mathrm{T}_{\mathrm{g}}$ decrease is more important for ISG glass composition as compared to $\mathrm{NH}$ glass composition. We linearly fitted the data to obtain the change in $\mathrm{T}_{\mathrm{g}}$ as a function of I content. The obtained equations reported in Figure 4 suggest that 1 mol. $\%$ I decreases $\mathrm{T}_{\mathrm{g}}$ by 38.5 and $8.2^{\circ} \mathrm{C}$ for ISG and NH glasses, respectively. Considering that I has the same dissolution behavior in both compositions (i.e. $\mathrm{I}^{-}$), it implies that the impact of I dissolution on the glass structure is not identical between the compositions. 


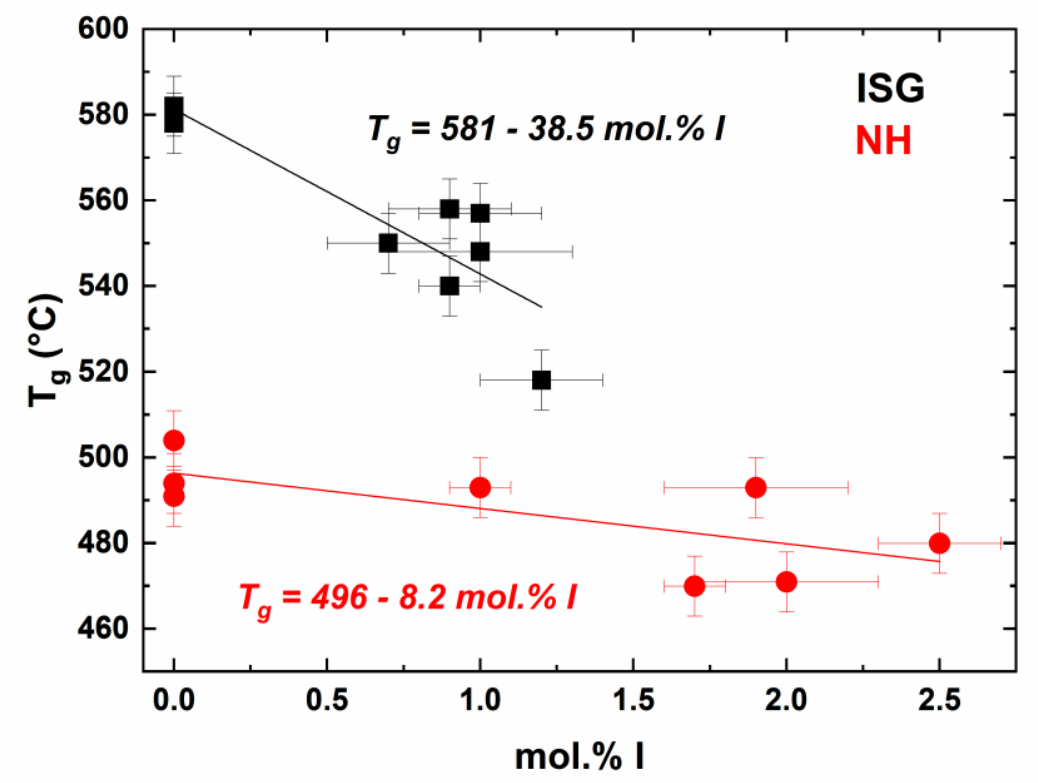

Figure 4: Change in $\mathrm{T}_{\mathrm{g}}$ value as a function of I content in mol.\% in both ISG and NH glasses. Increasing I content decreases $\mathrm{T}_{\mathrm{g}}$ and the slope for $\mathrm{T}_{\mathrm{g}}$ decrease is much more important in the case of ISG than NH as shown by the fitted linear trends.

The studied glasses were synthesized under high-pressure conditions. Hence, the effect of pressure conditions on $\mathrm{T}_{\mathrm{g}}$ needs to be addressed. From the structural point of view, pressure effect on $T_{g}$ is often associated to changes in the distribution of structural units within the glass structure; ${ }^{40,50,66}$ however, Smedskjaer et al.${ }^{67}$ invoked medium order change and packing of the structure to explain the change in macroscopic physical properties for borosilicate glasses. The effect of pressure on $\mathrm{T}_{\mathrm{g}}$ for borosilicate glasses is only poorly investigated. Ding et al. ${ }^{68}$ showed that viscosity (hence $\mathrm{T}_{\mathrm{g}}$ ) is slightly increasing with increasing pressure in industrial borosilicate glass. In the present work for ISG glasses, we observe a slight effect of pressure on $\mathrm{T}_{\mathrm{g}}$. For instance, for I-free ISG glasses, $\mathrm{T}_{\mathrm{g}}$ values are 577 and $578^{\circ} \mathrm{C}$ at ambient and $1.0 \mathrm{GPa}$, 
respectively. The same applies for I-bearing ISG glasses. At 0.9 mol.\% I, the change in $\mathrm{T}_{\mathrm{g}}$ is from 540 to $558^{\circ} \mathrm{C}$ between 0.5 and $1.5 \mathrm{GPa}$. These results point towards a slight increase in $\mathrm{T}_{\mathrm{g}}$ as a function of pressure for ISG samples that is consistent with the slight increase in viscosity reported by Ding et al. ${ }^{68}$ on a comparable glass composition (i.e. $70 \% \mathrm{SiO}_{2}$ and $11.5 \% \mathrm{~B}_{2} \mathrm{O}_{3}$ ). This slight increase in $\mathrm{T}_{\mathrm{g}}$ does not counterbalance the strong I effect as observed in Figure 4 for ISG glasses. For NH, it is less clear. For I-free NH glasses, we observe a decrease in $\mathrm{T}_{\mathrm{g}}$ with increasing pressure: $\mathrm{T}_{\mathrm{g}}$ is changing from 504 to $491^{\circ} \mathrm{C}$ between ambient and $1.5 \mathrm{GPa}$. However, at $\sim 2$ mol.\% I we observe an increase in $\mathrm{T}_{\mathrm{g}}$ from 471 to 480 and $493^{\circ} \mathrm{C}$ between 1.0 and $1.5 \mathrm{GPa}$. In the light of the results obtained on both glass compositions, the pressure effect is probably dependent on bulk composition; hence, further work is needed to determine the systematic evolution of $\mathrm{T}_{\mathrm{g}}$ as a function of borosilicate glass composition. Nonetheless, the pressure effect appears limited in the range of pressure investigated and compared to the I effect shown in Figure 4.

\section{Discussion}

\subsection{The impact of iodine on the local environment of the borosilicate glass and the relationship to $T g$}

We have shown from Figure 4 that $\mathrm{T}_{\mathrm{g}}$ is influenced by the presence of I and that increasing I decreases the $\mathrm{T}_{\mathrm{g}}$. Comparable behavior has been observed in previous work for B-rich borosilicate glass compositions. ${ }^{7}$ We also show that the influence of I on $\mathrm{T}_{\mathrm{g}}$ is not the same in between the compositions with a decreasing slope that is more important for ISG than for NH. Jolivet et al. ${ }^{8}$ demonstrated that the local environments of $\mathrm{Na}^{+}\left(\right.$or $\left.\mathrm{Ca}^{2+}\right)$ are involved in the I dissolution. The XPS results shown in Figure 2 indicates that the I dissolution mechanism is the 
same regardless of the glass composition. Riley et al. ${ }^{15}$ suggested that I dissolution in borosilicate glasses could be explained by the following reaction:

$$
3 \mathrm{I}_{2}^{\text {fluid }}+3 \mathrm{Na}_{2} \mathrm{O}^{\text {melt }} \leftrightarrow 5 \mathrm{NaI} \text { melt }+\mathrm{NaIO}_{3}^{\text {melt }}
$$

In this reaction, I is dissolved in the glass structure as $\mathrm{NaI}$ (a similar reaction could be written with $\mathrm{Ca}^{2+}$ ) but also as $\mathrm{NaIO}_{3}$. Except for $\mathrm{NH} 23-2$, we did not identify the presence of iodate molecular groups and certainly not with a ratio of 1:5 with iodide. Although it is out of the scope of this work, it implies that another mechanism has to be invoked to explain the I dissolution as $\mathrm{I}^{-}$ species. One hypothesis is that in the dissolution process, I atoms interact with the charges available on the borate and/or silicate networks. Actually, Jolivet et al. ${ }^{8}$ also showed that the borate network is affected by the I dissolution and variably as a function of composition. For instance, they showed that $\mathrm{N}_{4}$ value increases with increasing I content for $\mathrm{NH}$ whereas $\mathrm{N} 4$ decreases with increasing I content for ISG. Meanwhile, based on Raman spectroscopic results they mentioned that silicate network does not seem to be affected by the I dissolution. This latter aspect requires further investigations to be confirmed.

We have plotted in Figure 5 the change in $\mathrm{T}_{\mathrm{g}}$ as a function of $\mathrm{N}_{4}$ value as reported in Jolivet et al. ${ }^{8}$. For several samples (i.e. ISG21-2, 22-1, 13 and NH21-2) we have calculated an approximate value for $\mathrm{N}_{4}$ with a linear regression using the data from Jolivet et al. ${ }^{8}$. We observe two trends, one for each composition. To our opinion, there are competing effects: I content and change in the $\mathrm{N}_{4}$; that explain the difference on the slope for $\mathrm{T}_{\mathrm{g}}$ as a function of glass composition. Smedskjaer et al. ${ }^{51}$ showed that $\mathrm{T}_{\mathrm{g}}$ is a complex function of the glass composition and the structural arrangement in borosilicate glasses; however, globally an increasing $\mathrm{N}_{4}$ value is correlated to an increase in $\mathrm{T}_{\mathrm{g}}$ value (see figure 17 in Smedskjaer et al. ${ }^{51}$ ). It appears consistent with the fact that $\mathrm{BO}_{4}$ units represent the most polymerized unit in the boron network, namely 
tetrahedral boron is mostly surrounded by bridging oxygens. ${ }^{44}$ With analogy to the pure silicate glasses, there is a positive correlation between $\mathrm{T}_{\mathrm{g}}$ and the degree of polymerization.

Consequently, for ISG glass, I dissolution is accompanied by a decrease in $\mathrm{N}_{4}$, hence the slope of $\mathrm{T}_{\mathrm{g}}$ decrease will be steeper than for $\mathrm{NH}$ glass showing an increase in $\mathrm{N}_{4}$. The increase in the degree of polymerization for I-bearing $\mathrm{NH}$ glasses opposes to the I effect on $\mathrm{T}_{\mathrm{g}}$.

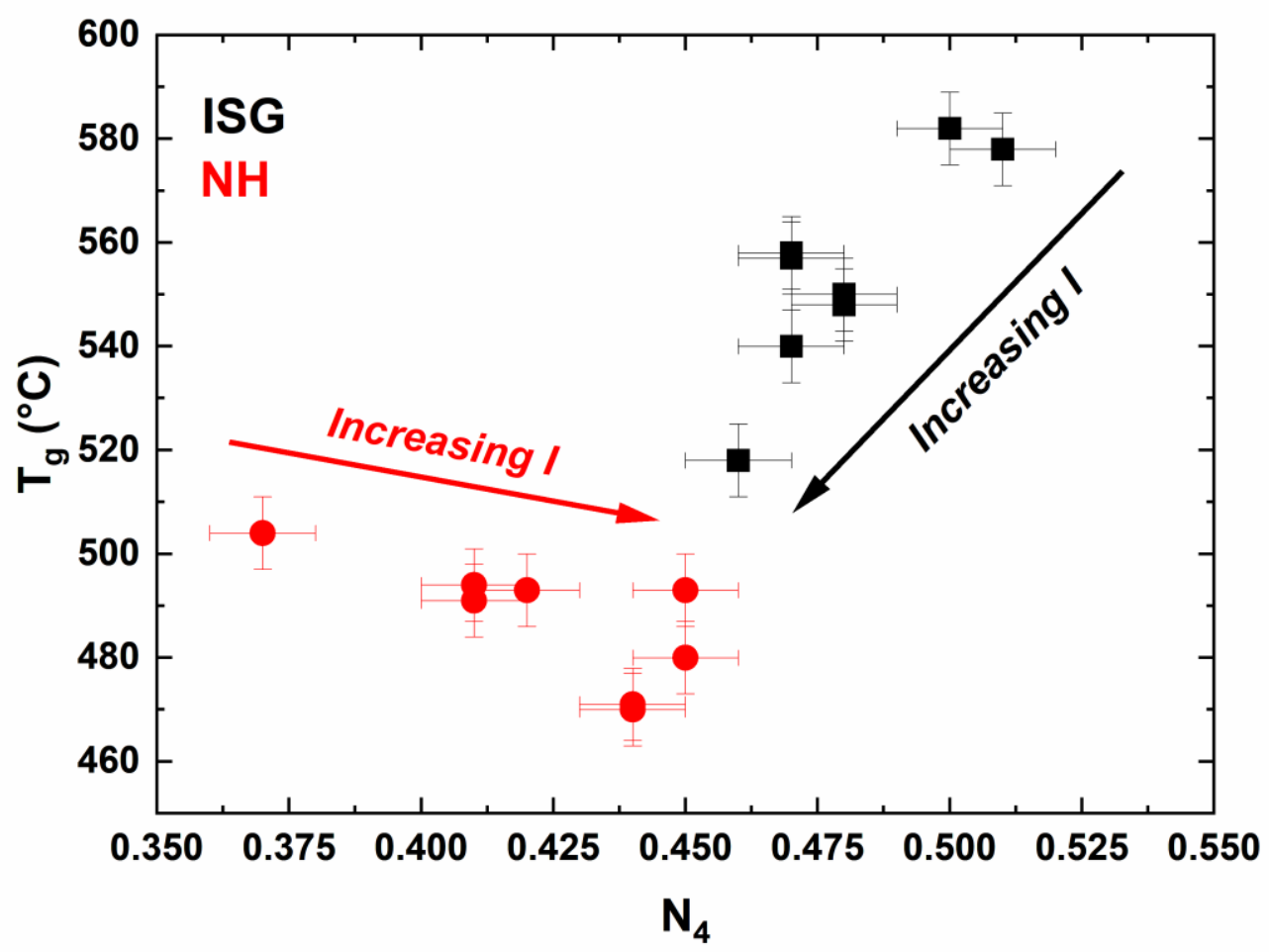

Figure 5: Change in $\mathrm{T}_{\mathrm{g}}$ as a function of $\mathrm{N}_{4}$ as provided by Jolivet et al. ${ }^{8}$ and determined from ${ }^{11} \mathrm{~B}$ NMR. The contrasting behavior between ISG and NH can be explained by the effect of I on the boron network: polymerizing for NH and depolymerizing for ISG. 
By analogy, the I dissolution is comparable to the dissolution of $\mathrm{CO}_{3}{ }^{2-}$ molecular groups in silicate melts. It has been shown ${ }^{69}$ that $\mathrm{CO}_{3}{ }^{2-}$ forms free ionic carbonates such as $\mathrm{M}^{\mathrm{n}+} \mathrm{CO}_{3}{ }^{2-}$ where $\mathrm{M}^{\mathrm{n}+}$ is a charge compensating cation (e.g. $\mathrm{Na}^{+}$or $\mathrm{Ca}^{2+}$ ). The proposed mechanism for I dissolution is similar in the sense that an alkaline (or alkaline-earth) cation is scavenged to compensate the negative charge of $\mathrm{I}^{-}{ }^{14,15}$ For $\mathrm{CO}_{2}$, such dissolution mechanism induces an increase in the degree of polymerization of the silicate network; however, a slight decrease in $\mathrm{T}_{\mathrm{g}}$ is observed. ${ }^{31}$ It was interpreted as resulting from the competing effect of the lower viscosity of carbonate melt ${ }^{70}$ and the higher viscosity of the silicate melt counterpart. For the I case, we suspect that similar reasoning can be adopted. In the case of $\mathrm{NH}$, the presence of Na-I will provoke a strong decrease in $\mathrm{T}_{\mathrm{g}}$ that is counterbalanced by the increase in the degree of polymerization of the borate network units (i.e. increasing $\mathrm{N}_{4}$ ) resulting in the lower slope observed in Figure 4 and Figure 5. On the contrary, for ISG, the I dissolution as Na-I is accompanied by a decrease in the degree of polymerization of the borate network units (i.e. decreasing $\mathrm{N}_{4}$ ) resulting in the steepest slope observed in Figure 4 and Figure 5. The nature of the chemical reactions involved in the polymerization changes for the borate network units is still debated; however, we suspect that the anionic species play a major role.

\subsection{Implication and perspectives for the immobilization of the ${ }^{129}$ I radioisotope in nuclear waste glasses}

Several waste forms have been considered for the immobilization of I radioisotopes with different levels of I concentrations; each having benefits and disadvantages. Riley et al. ${ }^{5}$ provided a review of the different waste forms that can be used to store a large quantity of I radioisotopes. Interesting candidates are Hot Isostatic Pressing of Ag-I crystalline compounds ( 5-10 mol.\% I), Ag-functionalized silica aerogel ( 15 mol.\% I), Ag-based phosphate glass (>10 mol.\% I). The 
current high-pressure borosilicate glasses do not represent the highest possible I concentrated waste form, however, the intrinsic high stability of the borosilicate glasses make them a good candidate for the immobilization of iodine.

The choice of a specific glass matrix for the immobilization of ${ }^{129} \mathrm{I}$ radioisotopes requires a high stability of the network through time, with regards to the thermal activity of radioisotopes and their decays, and high chemical and physical stability under environmental repository conditions (i.e. aqueous fluid circulation and composition, redox, $\mathrm{pH}$, pressure, temperature).

Although ${ }^{129}$ is not a strong thermo-active radioisotope ( $\beta-\gamma$ emitter), the recent advances in the development of specific incorporation matrix such as Ag-based phosphate ${ }^{71}$ and tellurite ${ }^{72}$ does not an entirely suitable solution considering the low $\mathrm{T}_{\mathrm{g}}$ of these materials $\left(<200^{\circ} \mathrm{C}\right)$.

At the observed level of I incorporation in the borosilicate glass matrix (up to $2.5 \mathrm{~mol} . \%$ ); it is unlikely that the $\mathrm{T}_{\mathrm{g}}$ will be low enough to reach a temperature at which the network structure is damaged. In first approximation, on a linear evolution of $\mathrm{T}_{\mathrm{g}}$ as a function of I content as shown in Figure $4 ; \sim 8 \mathrm{~mol} . \%$ are required for decreasing $\mathrm{T}_{\mathrm{g}}$ down to $\sim 200^{\circ} \mathrm{C}$ for ISG glass. Considering that iodine has less important impact on $\mathrm{T}_{\mathrm{g}}$ for $\mathrm{NH}$ than for ISG; we believe that $\mathrm{NH}$ glass that has a typical LAW glass composition is better suited for the specific immobilization of ${ }^{129}$ I. However, alteration experiments on such glass need to be assessed to evaluate the chemical durability.

Furthermore, Jolivet et al. ${ }^{8}$ showed that the proportion of $\mathrm{BO}_{4}$ units increases with increasing I content in $\mathrm{NH}$ glass; which could explain the lower slope for $\mathrm{T}_{\mathrm{g}}$ in Figure 4 . The $\mathrm{BO}_{4}$ structural unit in the boron network represents the most stable (because more polymerized) structural motif in comparison to $\mathrm{BO}_{3}$ (less polymerized). As a result, despite the decrease in $\mathrm{T}_{\mathrm{g}}$, 
the I-bearing NH glasses will tend to become more stable with the I dissolution considering the increase in $\mathrm{N}_{4}$ shown in Figure 5. Finally, recent work $^{73}$ has shown that the glass dissolution is affected by the $\mathrm{N}_{4}$ of the glass and that minimum dissolution rate is observed when the $\mathrm{N}_{4}$ is high. Again, in the present work I-bearing $\mathrm{NH}$ glass represents a potential adequate solution for the immobilization of ${ }^{129} \mathrm{I}$ as the I dissolution increases the $\mathrm{N}_{4}$.

Further work is currently requested to determine the I effect on $\mathrm{T}_{\mathrm{g}}$ for nuclear waste glasses. I dissolved as $\mathrm{I}^{-}$does not represent the most stable or immobile form for I. Iodate $\left(\mathrm{I}^{5+}\right)$ present as $\mathrm{IO}_{3}{ }^{-}$is the other I species, formed in oxidizing conditions due to the radiolysis effect ${ }^{74}$. In the context of a nuclear waste repository site in clay formation, it has been shown that the iodate form has a high affinity for clays. ${ }^{75}$ Thus, it would be of interest to determine the change in $\mathrm{T}_{\mathrm{g}}$ for $\mathrm{IO}_{3}{ }^{-}$-bearing borosilicate glasses.

\section{Summary}

In the present work, we have investigated the in glass transition temperature $\left(\mathrm{T}_{\mathrm{g}}\right)$ for a series of borosilicate glasses with composition relevant to nuclear waste immobilization and doped with iodine (I). The objective of this work was to determine the I effect on $\mathrm{T}_{\mathrm{g}}$ with the potential application of ${ }^{129} \mathrm{I}$ radioisotope immobilization in borosilicate glasses. We studied glasses (ISG and $\mathrm{NH}$ ) reported in Jolivet et al. ${ }^{8}$ and having I content ranging up to $2.5 \mathrm{~mol} \%$.

We have shown from XPS results that $\mathrm{I}$ is mostly dissolved as iodide species $\left(\mathrm{I}^{-}\right)$in consistency with previous investigations. DSC results show that increasing I content induces a decrease in $\mathrm{T}_{\mathrm{g}}$. However, this decrease is different as a function of glass composition. For instance, a more important decrease in $\mathrm{T}_{\mathrm{g}}$ is seen for ISG than for $\mathrm{NH}$. We ascribed this 
difference to the structural modifications of the boron network upon I dissolution as $\mathrm{I}^{-}$species. For NH, I dissolution polymerizes the boron network whereas it depolymerizes the boron network for ISG. Hence, in the latter case, there is combining effect on decreasing the $\mathrm{T}_{\mathrm{g}}$ value: presence of Na-I and depolymerization.

Although ISG glass composition is considered as a standard simulant glass for nuclear waste radioisotopes; the strong decrease in $\mathrm{T}_{\mathrm{g}}$ upon I dissolution questions the use of this glass composition for the particular case of ${ }^{129} \mathrm{I}$. A more specific glass matrix composition having 1) high $T_{g}$ value, 2) lower $T_{g}$ decrease and 3) accompanied by a polymerization effect with I dissolution would be more suitable. The LAW NH composition represents a good compromise as it dissolves large I amount, it has a high $\mathrm{T}_{\mathrm{g}}$ in comparison to the existing specific matrix for I conditioning (e.g. Ag-bearing phosphate glass) and I only decreases slightly $\mathrm{T}_{\mathrm{g}}$.

\section{Acknowledgement}

The authors are grateful to the Région Pays de la Loire, which financed the current work through the Pari Scientifique "CIPress". The authors thank the Laboratoire de Planétologie et Géodynamique, the Institut des Matériaux Jean Rouxel, Institut Mines-Telecom Atlantique, the University of Nantes and the CNRS for providing access to the analytical facilities. We wish to thank Eric Chevrel from IMT Atlantique for his assistance with the DSC measurements. We wish to thank Prof. Du and two anonymous reviewers for their fruitful comments to improve the manuscript. 


\section{References}

1. Bureau H, Auzende A-L, Marocchi M, et al. Modern and past volcanic degassing of iodine. Geochim Cosmochim Acta. 2016; 173:114-125.

2. Leroy C, Bureau H, Sanloup C, et al. Xenon and iodine behaviour in magmas. Earth Planet Science Lett. 2019; 522:144-154.

3. Hmra P. Retention of halogens in waste glass. U.S. department of energy, 2010.

4. McKeown DA, Muller IS, Pegg IL. Iodine valence and local environments in borosilicate waste glasses using X-ray absorption spectroscopy. J Nuc Mat. 2015; 456:182-191.

5. Riley BJ, Vienna JD, Strachan DM, McCloy JS, Jerden JLJr. Materials and processes for the effective capture and immobilization of radioiodine: A review. J Nuc Mat. 2016; 470:307-326.

6. Cicconi MR, Pili E, Grousset L, Neuville DR. The influence of glass composition on iodine solubility. Mat Res Soc. 2019a; 4:17-18.

7. Cicconi MR, Pili E, Grousset L, Florian P, Bouillard JC, Vantelon D, Neuville DR. Iodine solubility and speciation in glasses. Sci Rep. 2019b; 9:7758.

8. Jolivet V, Morizet Y, Paris M, Suzuki-Muresan T. High pressure experimental study on iodine solution mechanisms in nuclear waste glasses. J Nuc Mat. 2020; 533:152112.

9. Raisbeck MFX, Yiou GM. Measurements of carrier free ${ }^{129} \mathrm{I} /{ }^{127} \mathrm{I}$ in environmental samples by accelerator mass spectrometry. Min Mag. 1999; 62:953-954.

10. Aldahan A, Alfimov V, Possnert G. ${ }^{129}$ I anthropogenic budget: Major sources and sinks. App Geochem. 2007; 22:606-618. 
11. Tournassat C, Gaucher EC, Fattahi M, Grambow B. On the mobility and potential retention of iodine in the Callovian-Oxfordian formation. Phys Chem Earth. 2007; 32:539-551.

12. Reithmeier H, Lazarev V, Rühm W, Nolte E. Anthropogenic ${ }^{129} \mathrm{I}$ in the atmosphere: Overview over major sources, transport processes and deposition pattern. Sci Tot Env. 2010; 408:5052-5064.

13. Chen X, Gong M, Yi P, Aldahan A, et al. Distribution of ${ }^{129} \mathrm{I}$ in terrestrial surface water environments. Nuc Inst Meth Phys Res B. 2015; 361:604-608.

14. Muller IS, McKeown DA, Pegg IL. Structural behavior of Tc and I Ions in nuclear waste glass. Proc Mater Sci. 2014; 7:53-59.

15. Riley BJ, Schweiger MJ, Kim DS, et al. Iodine solubility in a low-activity waste borosilicate glass at $1000^{\circ} \mathrm{C}$. J Nuc Mat. 2014; 452:178-188.

16. Ojovan MI, Lee WE. Connectivity and glass transition in disordered oxide systems. J NonCryst Solids. 2010; 356:2534-2540.

17. Dingwell DB, Webb SL. Relaxation in silicate melts. Eur J Min. 1990; 2:427-449.

18. Moynihan CT, Easteal AJ, DeBolt MA, Tucker J. Dependence of fictive temperature of glass on cooling rate. J Am Cer Soc. 1976; 59:12-16.

19. Boekenhauer R, Zhang H, Feller S, et al. The glass transition temperature of lithium borosilicate glasses related to atomic arrangements. J Non-Cryst Solids. 1994; 175:137-144.

20. Avramov I, Vassilev Ts, Penkov I. The glass transition temperature of silicate and borate glasses. J Non-Cryst Solids. 2005; 351:472-476. 
21. Maji BK, Jena H, Asuvathraman R. Electrical conductivity and glass transition temperature $\left(\mathrm{T}_{\mathrm{g}}\right)$ measurements on some selected glasses used for nuclear waste immobilization. J Non-Cryst Solids. 2016; 434:102-107 (2016).

22. Raut AP, Deshpande VK. Influence of alumina addition and gamma irradiation on the lithium borosilicate glasses. Rad Phys Chem. 2018; 149:118-125.

23. Mazurin OV, Streltsina MV, Shvaiko-Shvaikovskaya TP. Handbook of Glass Data: Part A. Silica Glass and Binary Silicate Glasses. Physical Science Data 15, Amsterdam: Elsevier; 1983.

24. Neyret M, Lenoir M, Grandjean A, Massoni N, Penelon B, Malki M. Ionic transport of alkali in borosilicate glass. Role of alkali nature on glass structure and on ionic conductivity at the glassy state. J Non-Cryst Solids. 2015; 410:74-81.

25. Shih Y-T, Jean JH. Mixed modifier effect in lithium-calcium borosilicate glasses. J Am Cer Soc. $2017 ; 100: 5482-5489$.

26. Whittington A, Richet P, Linard Y, Holtz F. The viscosity of hydrous phonolites and trachytes. Chem Geol. 2001; 174:209-223.

27. Deubener J, Muller R, Behrens H, Heide G. Water and the glass transition temperature of silicate melts. J Non-Cryst Solids. 2003; 330:268-273.

28. Giordano D, Russell JK, Dingwell DB. Viscosity of magmatic liquids: a model. Earth Planet. Science Lett. 2008; 271:123-134.

29. Behrens H, Bauer U, Reinsch S, Kiefer P, Müller R, Deubener J. Structural relaxation mechanisms in hydrous sodium borosilicate glasses. J Non-Cryst Solids. 2018; 497:30-39. 
30. Morizet Y, Nichols ARL, Kohn SC, Brooker RA, Dingwell DB. The influence of $\mathrm{H}_{2} \mathrm{O}$ and $\mathrm{CO}_{2}$ on the glass transition temperature: insights into the effects of volatiles on magma viscosity. Eur J Mineral. 2007; 19:657-669.

31. Morizet Y, Paris M, Sifre D, Di Carlo I, Ory S, Gaillard F. Towards the reconciliation of viscosity change and $\mathrm{CO}_{2}$-induced polymerization in silicate melts. Chem Geol. 2017a; 458:3847.

32. Sandland TO, Du L-S, Stebbins JF, Webster JD. Structure of Cl-containing silicate and aluminosilicate glasses: A ${ }^{35} \mathrm{Cl}$ MAS-NMR study. Geochim Cosmochim Acta. 2004; 68:50595069.

33. Zimova M, Webb SL. The combined effects of chlorine and fluorine on the viscosity of aluminosilicate melts. Geochim Cosmochim Acta. 2007; 71:1553-1562.

34. Evans KA, Mavrogenes JA, O’Neill HS, Keller NS, Jang L-Y. A preliminary investigation of chlorine XANES in silicate glasses. Geochem Geophys Geosys. 2008; 9:Q10003.

35. Zhao W, Li K, Lin P, Xu K, Tan S. Dissolution of $\mathrm{Cl}$ in alkaline earth (Ca, Sr, Ba) aluminosilicate glasses. J Non-Cryst Solids. 2019; 56:56-62.

36. Volf MB. Glass Science and Technology, 7: Chemical approach to Glass. Elsevier Scientific Publishers, New York; 1984.

37. Giordano D, Russell JK. A rheological model for glassforming silicate melts in the systems CAS, MAS, MCAS. J Phys Condens Matter. 2007; 19:255148-255159.

38. Mysen BO. Effect of pressure, temperature and bulk composition on the structure and species distribution in depolymerised alkali aluminosilicate melts and quenched melts. J Geophys Res B. 1990; 95:15733-15744. 
39. Doweidar H. Density-structure correlations in silicate glasses. J Non-Cryst Solids. 1999; 249:194-200.

40. Allwardt JR, Stebbins JF, Terasaki H, et al. Effect of structural transitions on properties of high-pressure silicate melts: ${ }^{27}$ Al NMR, glass densities, and melt viscosities. Am Mineral. 2007; 92:1093-1104.

41. Guillot B, Sator N. A computer simulation study of natural silicate melts. Part II: high pressure properties. Geochim Cosmochim Acta. 2007; 71:4538-4556.

42. Dell WJ, Bray PJ, Xiao SZ. ${ }^{11} \mathrm{~B}$ NMR studies and structural modeling of $\mathrm{Na}_{2} \mathrm{O}-\mathrm{B}_{2} \mathrm{O}_{3}-\mathrm{SiO}_{2}$ glasses of high soda content. J Non-Cryst Solids. 1983; 58:1-16.

43. Wang S, Stebbins JF. Multiple-Quantum Magic-Angle Spinning ${ }^{17}$ O NMR studies of borate, borosilicate, and boroaluminate glasses. J Am Cer Soc. 1999; 82:1519-1528.

44. Du LS, Stebbins JF. Network connectivity in aluminoborosilicate glasses: A high-resolution ${ }^{11} \mathrm{~B},{ }^{27} \mathrm{Al}$ and ${ }^{17} \mathrm{O}$ NMR study. J Non-Cryst Solids. 2005; 351:3508-3520.

45. Holland D, Parkinson BG, Islam MM., et al. NMR insights into wasteforms for the vitrification of high-level nuclear waste. Appl Magn Reson. 2007; 32:483-497.

46. Angeli F, Charpentier T, Gaillard M, Jollivet P. Influence of zirconium on the structure of pristine and leached soda-lime borosilicate glasses: Towards a quantitative approach by ${ }^{17} \mathrm{O}$ MQMAS NMR. J Non-Cryst Solids. 2008; 354:3713-3722.

47. Holbrook C, Chakraborty S, Ravindren S, Boolchand P, Goldstein JT, Stutz CE. Topology and glass structure evolution in $(\mathrm{BaO})_{\mathrm{x}}\left(\left(\mathrm{B}_{2} \mathrm{O}_{3}\right)_{32}\left(\mathrm{SiO}_{2}\right)_{68}\right)_{100 \text { - } \mathrm{x}}$ ternary- Evidence of rigid, intermediate, and flexible phases. J Chem Phys. 2014; 140:144506. 
48. Jolivet V, Jossé L, Rivoal M, et al. Quantification of boron in aluminoborosilicate glasses using Raman and ${ }^{11}$ B NMR. J Non-Cryst Solids. 2019; 511:50-61.

49. Du LS, Stebbins JF. Solid-state NMR study of metastable immiscibility in alkali borosilicate glasses. J Non-Cryst Solids. 2003; 315:239-255.

50. Du LS, Allwardt JR, Schmidt BC, Stebbins JF. Pressure-induced structural changes in a borosilicate glass-forming liquid: Boron coordination, non-bridging oxygens, and network ordering. J Non-Cryst Solids. 2004; 337:196-200.

51. Smedskjaer MM, Mauro JC, Youngman RE, Hogue CL, Potuzak M, Yue Y. Topological principles of borosilicate glass chemistry. J Phys Chem B. 2011; 115:12930-12946.

52. Inagaki Y, Kikunaga T, Idemitsu K, Arima T. Initial dissolution rate of the International Simple Glass as a function of $\mathrm{pH}$ and temperature measured using microchannel flow-through test method. Int J App Glass Sci. 2003; 4:317-327.

53. Gin S, Jollivet P, Fournier M, Angeli F, Frugier P, Charpentier T. Origin and consequences of silicate glass passivation by surface layers. Nature Comm. 2015; 6:1-8.

54. Elia A, Ferrand K, Lemmens K. Determination of the forward dissolution rate for international simple glass in alkaline solutions. MRS Adv. 2017; 12:661-667.

55. Abdelouas A, El Mendili Y, Aït Chaou A, et al. A preliminary investigation of the ISG glass vapor hydration. Int J Appl Glass Sci. 2013; 4:307-316.

56. Charpentier T, Martel L, Mir AH, Somers J, Jégou C, Peuget S. Self-healing capacity of nuclear glass observed by NMR spectroscopy. Sci Rep. 2016; 6:25499. 
57. Gin S, Abdelouas A, Criscenti LJ, et al. An international initiative on long-term behavior of high-level nuclear waste glass. Mater Today. 2013; 16:243-248.

58. Tougaard S. Universality classes of inelastic electron scattering cross-sections. Surf Inter Anal. 1997; 25:137-154.

59. Tojo T, Tachikawa T, Fujitsuka M, Majima T. Iodine-doped $\mathrm{TiO}_{2}$ photocatalysts: Correlation between band structure and mechanism. J Phys Chem C. 2008; 112:14948-14954.

60. Li K, Zhao Y, Zhang P, et al. Combined DFT and XPS investigation of iodine anions adsorption on the sulfur terminated (001) chalcopyrite surface. App Surf Science. 2016; 390:412421.

61. Moulder JF, Stickle WF, Sobol PE, Bomben KD. Handbook of W-ray Photoelectron Spectroscopy: a reference book of standard spectra for identification and interpretation of XPS spectra. J Chastain Ed., Perkin-Elmer Corporation Physical Electronics Division, Eden Prairie, Minnesota; 1992.

62. Kägi R, Müntener O, Ulmer P, Ottolini L. Piston-cylinder experiments on $\mathrm{H}_{2} \mathrm{O}$ undersaturated Fe-bearing systems: An experimental setup approaching $\mathrm{fO}_{2}$ conditions of natural calc-alkaline magmas. Am Mineral. 90:708-717.

63. Gong YX, Wren AW, Mellott NP. Quantitative morphological and compositional evaluation of laboratory prepared aluminoborosilicate glass surfaces. App Surf Science. 2015; 324:594-604.

64. Guerette M, Huang L. In-situ Raman and Brillouin light scattering study of the international simple glass in response to temperature and pressure. J Non-Cryst Solids. 2015; 411, 101-105.

65. Kaspar TC, Ryan JV, Pantano CG, et al. Physical and optical properties of the International Simple Glass. Nature Mat. Degrad. 2019; 3:1-15. 
66. Bista S, Stebbins JF, Wu J, Gross TM. Structural changes in calcium aluminoborosilicate glasses recovered from pressures of 1.5 to $3 \mathrm{GPa}$ : Interactions of two network species with coordination number increases. J Non-Cryst Solids. 2017; 478:50-57.

67. Smedskjaer MM, Youngman RE, Striepe S, et al. Irreversibility of pressure induced boron speciation change in glass. Sci Rep. 2014; 4:3770.

68. Ding L, Thieme M, Demouchy S, Kunisch C, Kaus BJP. Effect of pressure and temperature on viscosity of a borosilicate glass. J Am Cer Soc. 2018; 101:3936-3946.

69. Morizet Y, Florian P, Paris M, Gaillard F. ${ }^{17} \mathrm{O}$ NMR evidence of free ionic clusters $\mathrm{M}^{\mathrm{n}+}$ $\mathrm{CO}_{3}{ }^{2-}$ in silicate glasses: Precursors for carbonate-silicate liquids immiscibility. Am Mineral. 2017b; 102:1561-1564.

70. Kono Y, Kenney-Benson C, Hummer D, et al. Ultralow viscosity of carbonate melts at high pressures. Nature Comm. 2014; 5:5091.

71. Chabauty A-L, Campayo L, Méar FO, Montagne L. Niobium- and bismuth-silver phosphate glasses for the conditioning of radioactive iodine. J Non-Cryst Solids. 2019; 510, 51-61.

72. Lee CW, Pyo J-Y, Park HS, Yang JH, Heo J. Immobilization and bonding scheme of radioactive iodine-129 in silver tellurite glass. J Nuc Mat. 2017; 492:239-243.

73. Goetschius KL, Beuerlein MA, Bischoff CM, Brow RK. Dissolution behavior of ternary alkali-alkaline earth-borate glasses in water. J Non-Cryst Solids. 2018; 487:12-18.

74. Lin CC. Chemical behavior of radioiodine in BWR systems-I. Inorg Nuc Chem. 1979; 42:1093-1099. 
75. Kaplan DI, Serne RJ, Parker KE, Kutnyakov IV. Iodide sorption to subsurface sediments and illitic minerals. Env Sci Tech. 2000; 34:399-405. 